\title{
G-435 and ARS 96-138, Pink-fruited Blueberry Selections
}

\author{
Mark K. Ehlenfeldt ${ }^{1}$
}

U.S. Department of Agriculture, Agricultural Research Service, Marucci Center for Blueberry and Cranberry Research and Extension, 125A Lake Oswego Road, Chatsworth, NJ 08019

\section{Chad E. Finn}

U.S. Department of Agriculture, Agricultural Research Service, Northwest Center for Small Fruit Research, 3420 NW Orchard Avenue, Corvallis, OR 97330

Additional index words. fruit breeding, Vaccinium corymbosum, Vaccinium ashei, tetraploid, landscape

\begin{abstract}
G-435 and ARS 96-138 are two pink-fruited blueberry selections developed by the Agricultural Research Service of the U.S. Department of Agriculture. G-435, a tetraploid, is predominantly Vaccinium corymbosum L. (highbush blueberry) with a mixture of other Vaccinium species germplasm in its ancestry. It has been evaluated in New Jersey and Michigan. ARS 96-138 is a hexaploid that is half $V$. ashei Reade (rabbiteye blueberry) and half synthetically derived, hexaploid, highbush-type germplasm. It has been evaluated in New Jersey and Oregon. ARS 96-138 was partially derived from a pink-fruited sibling of G-435; thus, the two selections are related, although they possess different ploidy levels. They are released as germplasm for further evaluation, breeding, and possible commercialization. They represent a novel fruit color in blueberry that is of interest to the landscape nursery business.
\end{abstract}

Coville (1937) listed the descriptions and origins of numerous early blueberry cultivars released over the span of his career. Among them were two varieties he described as "albino," but which are more correctly described as albescent or pink-fruited. These were 'Redskin' and 'Catawba'. Coville stated, "They were given names in 1932 because as red-cheeked albinos they are horticultural curiosities". He further commented, "It is doubtful whether any albino blueberry will ever acquire importance as a market fruit." 'Redskin' and 'Catawba' apparently were never grown commercially and were ultimately lost even from their limited horticultural cultivation as garden curiosities. It is ironic that more than 70 years later, there is renewed interest in these plant materials. The Univ. of Florida patented and released a pinkfruited rabbiteye ( $V$. ashei Reade) cultivar in 2004 ('Florida Rose'; Lyrene, 2004), and the U.S. Department of Agriculture blueberry breeding program has received several inquiries from the landscape and nursery industry regarding two pink-fruited blueberry selections in its test plots. Because of this interest, the U.S. Department of Agriculture, Agricultural Research Service has released these selections for evaluation, breeding, and possible commercialization. Limited evaluations of pink-colored blueberry fruit quality have been made, and the fruit have generally

Received for publication 7 Apr. 2006. Accepted for publication 30 Aug. 2006.

${ }^{1}$ To whom reprint requests should be addressed; e-mail mehlenfeldt@ars.usda.gov. and pleasantly flavored (Ehlenfeldt, personal observation).

\section{Origins}

G-435 is tetraploid $(2 n=4 x=48)$ and predominantly Vaccinium corymbosum L. (highbush) with a mixture of other Vaccinium species germplasm in its ancestry. It results from a cross of G-132 × 290-1 (Fig. 1). The cross that produced G-435 was made by A.D. Draper at Beltsville, Md. The seedling was selected in 1978 at the Atlantic Blueberry Company in Hammonton, N.J. The selection was subsequently evaluated by A.D. Draper between 1981 and 1984 in Hammonton, N.J., and also evaluated at Michigan Blueberry Growers (MBG) Association test plots in Grand Junction, Mich.

ARS 96-138 is a hexaploid $(2 n=6 x=72)$ that is half $V$. ashei Reade (rabbiteye) and half synthetically derived, hexaploid, highbush-type germplasm. It results from a cross of NJ 89-158-1 × 'Delite' ( $V$. ashei) (Fig. 2). The female parent, NJ 89-158-1, was produced by Dr. Nicholi Vorsa (Rutgers Univ.). The cross that produced ARS 96-138 was made by M.K. Ehlenfeldt at Chatsworth, N.J., in 1991 and was selected in 1996 at the Marucci Center for Blueberry \& Cranberry Research and Extension, in Chatsworth, N.J. The selection was subsequently evaluated by M.K. Ehlenfeldt between 1996 and 2004 in New Jersey and also evaluated by C.E. Finn at USDA-ARS/Oregon State Univ. test plots in Corvallis, Ore. (Ehlenfeldt et al., 1994) sometimes to the point of being bland, but are often delicately

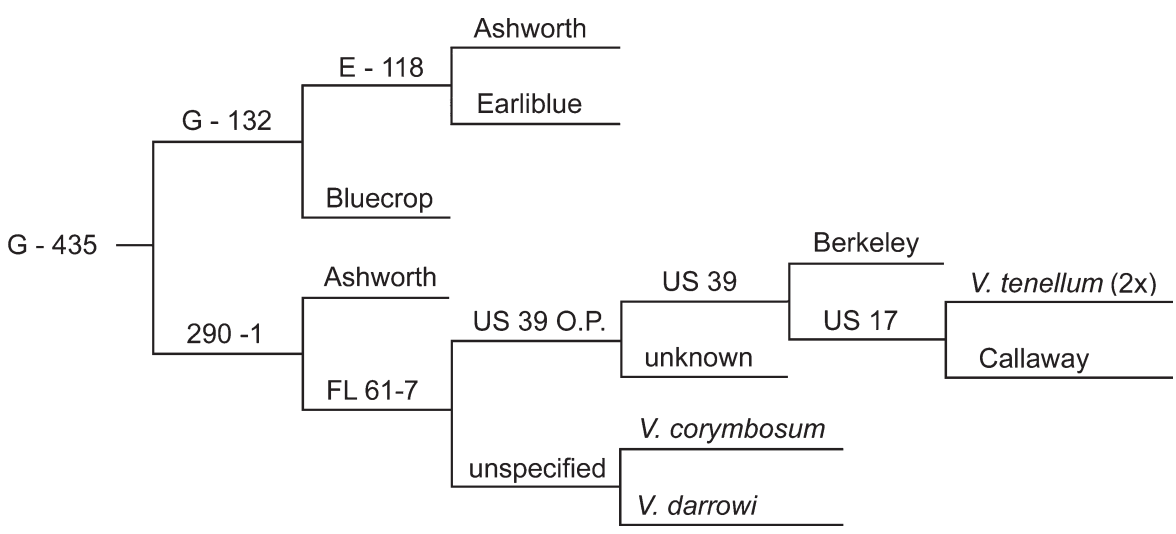

Fig. 1. Pedigree of G-435, pink-fruited blueberry.

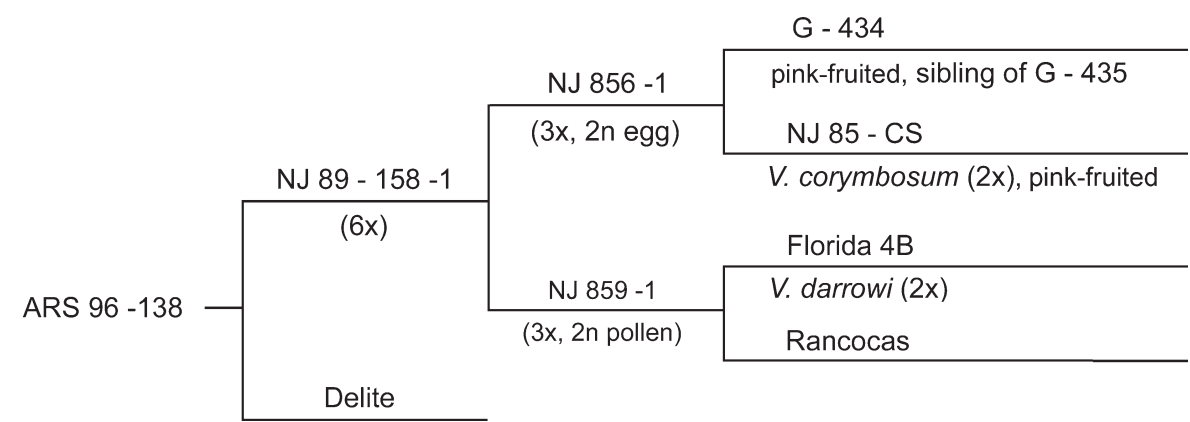

Fig. 2. Pedigree of ARS 96-138, pink-fruited blueberry. 
Table 1. Characteristics of G-435 in New Jersey.

\begin{tabular}{|c|c|c|c|c|c|c|}
\hline Year & Size & Scar & Firmness & Flavor & Productivity & Season \\
\hline 1981 & 7 & 8 & 8 & 7 & 8 & 8 \\
\hline 1982 & $7-8$ & 8 & 8 & 7 & 8 & 7 \\
\hline 1983 & $6-7$ & 8 & 8 & 8 & 7 & 8 \\
\hline 1984 & 7 & 8 & 8 & 7 & 3 & 7 \\
\hline
\end{tabular}

Ratings on a 1-9 scale with $1=$ worst, $9=$ best. Season of ripening rated as $1=$ latest, $9=$ earliest.

Table 2. Fruit color characteristics of G-435 in Michigan and ARS 96-138 in New Jersey

\begin{tabular}{lllr}
\hline Color & $\mathrm{L}^{\mathrm{z}}$ & $\mathrm{a}$ & $\mathrm{b}$ \\
\hline G-435 & & & \\
$\quad$ Pink (ripe with wax) & 81 & 18 & -7 \\
$\quad$ Dark pink & 56 & 49 & 18 \\
$\quad$ (ripe without wax) & & & \\
ARS 96-138 & & & \\
$\quad$ Dark pink (very ripe) & 59 & 67 & 27 \\
$\quad$ Pink (typical) & 71 & 48 & 5 \\
$\quad$ Green & 89 & -6 & 48 \\
\hline
\end{tabular}

${ }^{\mathrm{z}}$ Color in the $\mathrm{L}^{*} \mathrm{a} \mathrm{b}^{*}$ color coordinate system as defined by the Commission Internationale 1 'Eclairage (CIE). Color values were taken from the digital images in Figures $3 \mathrm{~A}$ and B.
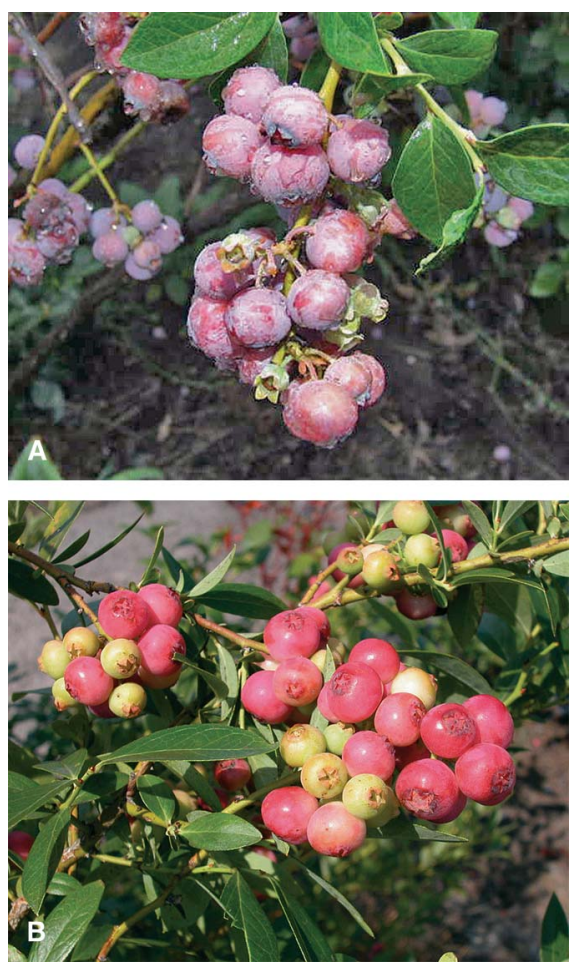

Fig. 3. (A) Fruit of G-435, pink-fruited blueberry. (B) Fruit of ARS 96-138, pink-fruited blueberry.

\section{Descriptions}

The general characteristics of G-435 are early- to midseason ripening, moderate to good yields, medium-sized fruit (1.3 g), dark pink fruit color, good flavor, good scar, and good firmness. Fruit quality may be considered comparable to 'Bluecrop' except for size; 'Bluecrop' typically averages $\approx 1.7 \mathrm{~g}$ per fruit. G-435 was considered to belong to the second-early ripening category in New Jersey and the midseason ripening category in Michigan. The evaluations in Michigan, from 2001 to 2003, recorded typical yields of $2.7 \mathrm{~kg}$ per bush with an average first harvest date of 25 July. Production was variable in New Jersey and is probably related to the southern germplasm in the ancestry of G-435, resulting in sporadic flower bud hardiness problems resulting from fluctuating late Winter temperatures. In higher yielding years (productivity $=8$ ), yields would be generally comparable to those of 'Bluecrop', which had yields of 4 to $5 \mathrm{~kg}$ per bush. Tables 1 and 2 list ratings and color data for G-435; Figure $3 \mathrm{~A}$ shows fruit of G-435. The bush of G-435 is upright and typical of highbush (1.5-m high $\times$ $1.2-\mathrm{m}$ wide). Summer foliage is deep green, turning to bright red in the fall. Winter twigs are burgundy in color. G-435 is recommended primarily for areas where northern highbush are typically grown, but the southern germplasm in its ancestry suggests it may also be adapted to more southerly areas.

The general characteristics of ARS 96-138 are: mid-late- to late-season ripening, moderate yields, medium-sized, glossy fruit, bright pink fruit color, mild pleasant flavor, and good firmness. Table 2 lists color data for ARS 96138; Figure 3B shows fruit of ARS 96-138. The bush of ARS 96-138 is vigorous, upright, and full (1.5-m high $\times 1.6-\mathrm{m}$ wide). Leaves are glossy, green, and lanceolate with serrated leaf margins. The leaf surface texture is smooth and very similar to that of $V$. ashei. Winter twigs are dusky reddish brown in color. Limited observations suggest that ARS 96138 has some resistance to the blighting phase of Monilinia vaccinii-corymbosi (mummy berry). Flowering time is similar to other southern blueberry germplasm with flowers developing earlier than those of hardy northern cultivars such as 'Bluecrop'. These plants are hardy in New Jersey, but fruit production is irregular, producing reduced or no crops in years with late spring frosts, and moderate crops in years with mild spring temperatures. Cropping ability is most likely related to flower bud deacclimation and hardiness in spring. The ideal area of adaptation of ARS 96-138 is unknown, but its background suggests that it might perform equally well, or better, in milder climates, including areas where rabbiteye cultivars can be grown. Because of the inherent self-fertility problems of rabbiteye germplasm, it is recommended that another rabbiteye cultivar be planted with ARS 96-138 to ensure good cross-pollination. In some southerly locales, the cultivar Florida Rose (Lyrene, 2004), a pink-fruited cultivar recently released by the University of Florida, may be suitable for this purpose.

These selections have consistently attracted the attention of visiting researchers, nurserymen, and consumers. It is believed that the ongoing interest in these selections reflects their potential appeal for landscape planting and for the novelty/specialty fruit market. These selections are released unconditionally with no warranties given regarding their performance or adaptation under specific environmental or cultural conditions.

\section{Availability}

Genetic material of this release has been deposited in the National Plant Germplasm System where it will be available for research purposes. Limited numbers of plants of G-435 and ARS 96-138 have been distributed to commercial nurseries for evaluation and possible commercialization. Commercial growers may request information on how to obtain propagules by contacting M.K. Ehlenfeldt, USDA-ARS, Marucci Center for Blueberry \& Cranberry Research and Extension, 125A Lake Oswego Road, Chatsworth, N.J. 08019 .

\section{Literature Cited}

Coville, F.V. 1937. Improving the wild blueberry, p. 559-574. In: Yearbook of agriculture-1937, U.S. Dept. Agr., Washington, D.C.

Ehlenfeldt, M.K., F.I. Meredith, and J.R. Ballington. 1994. Unique organic acid profile of rabbiteye versus highbush blueberries. HortScience 29:321-323.

Lyrene, 2004. Blueberry Plant Called 'Florida Rose'. U.S. Plant Patent 14,485 filed 4 Dec. 2002 and issued 27 Jan. 2004. 